\title{
Rutura psicótica e a vivência analítica
}

\section{Sandra Oliveira}

\begin{abstract}
Resumo
A autora parte de pressupostos essenciais acerca do processo de simbolização e da sua falha para abordar a forma como os elementos não nomeados e não representados que residem na parte psicótica da mente do paciente mantêm uma área da mente inacessível ao processo analítico, potenciando assim a eclosão de uma rutura psíquica grave. Tais ruturas são, por vezes, tão surpreendentes quanto inesperadas e colocam dificuldades incontornáveis na vivência e manejo do processo analítico. Sublinha-se então a importância do setting interno do analista enquanto película contentora suficientemente capaz de transformar e integrar os diferentes fenómenos que ocorrem na sessão analítica.
\end{abstract}

\section{Palavras-Chave}

Rutura psicótica, Vivência analítica, Falha na simbolização

Freud fundou a psicanálise tomando como base essencial o problema neurótico da simbolização. Ou seja, algo que é reprimido é substituído por um símbolo que o representa. Estes elementos ou símbolos são especialmente úteis justamente porque são substitutos, e como tal "disfarçam” a coisa original que está a ser substituída e assim preservam o elemento inconsciente irreconhecível. Ambos, a coisa original e o processo de substituição não são conscientes.

Todavia, sabemos também como Freud compreendeu que na psicose a simbolização é de uma ordem francamente diferente. De acordo com

1 Comunicação apresentada na II Jornada Clínica do IFTP do Porto, em fevereiro de 2018.

2 PHD. Psicanalista. Membro Associado da Sociedade Portuguesa de Psicanálise/IPA.E-mail: sandraoliveira442@gmail.com

(c) do Autor 2021. Publicado online em https://rppsicanalise.org, sob a Licença Creative Commons Atribuição-NãoComercial 4.O Internacional. Seguindo a exigência da preservação do anonimato dos pacientes e da confidencialidade, o material clínico é apresentado com alteração da identidade do paciente e de dados clínicos. a sua hipótese original, existem casos em que a consciência se vê invadida por conteúdos inconscientes, sobre os quais a ação da repressão não pode ser concretizada. Emergem assim como que uma espécie de corpos estranhos, sem representação simbólica, dando-nos conta como o inconsciente se apresenta como um mundo também ele estranho ao sujeito.

Hanna Segal (1957) descreveu de forma muito clara como a formação simbólica é responsável pela capacidade de comunicar, posto que toda a comunicação é feita através de símbolos. Ora, os símbolos são necessários não só para a comunicação do sujeito com o mundo externo, como também, e de um modo particularmente relevante, para a sua comunicação interna.

Temos, portanto, uma dificuldade que se nos coloca perante pacientes de funcionamento mais primitivo, e que reside em dois aspetos coexistentes: o paciente não pode comunicar connosco, mas não consegue também comunicar com ele 
próprio (ou com diferentes partes dele próprio). Logo, a possibilidade de integração das ansiedades e fantasias mais primitivas resulta bastante condicionada.

O estranho apresenta-se, assim, ao sujeito como uma realidade mental incompreensível e subsequentemente ameaçadora.

Em linha com as ideias até aqui enunciadas, temos presente o modelo de compreensão do funcionamento psicótico de Bion (1957; 1963) baseado no contraste entre uma parte psicótica da personalidade e uma parte não psicótica. Fundamentado no seu vasto trabalho com pacientes psicóticos, grandemente responsável pela formação da sua teoria do pensamento, e ao debruçar-se sobre o funcionamento psicótico referia-se não só ao paciente claramente diagnosticado com uma psicose, mas também à parte psicótica da personalidade em pacientes neuróticos e borderline. Nesta perspetiva entende-se, portanto, que em qualquer personalidade a dominância da parte psicótica sobre a não psicótica, num qualquer momento do percurso existencial, é algo que interfere profundamente no funcionamento mental do sujeito.

O ego psicótico remete para o lugar onde o sujeito, por intolerância à dor e à frustração causados pela exposição a conteúdos extraordinariamente dolorosos, vinca a falha da capacidade de transformar as suas experiências em pensamento. Assim, os conteúdos e experiências emocionais na vez de adquirirem um significado, ou uma representação mental significante, são antes esvaziados e destituídos de qualquer sentido.

Esta falha, ou como diria Segal (1957), a falha da função de formar símbolos quebra não só o vínculo comunicativo interno do sujeito, como a normal comunicação com o analista.

Quando o psicanalista entra em contacto com as áreas não simbólicas do paciente, e, em situações mais graves, é confrontado com uma rutura psicótica, encontra-se também ele em contato com a quebra de uma interação potenciadora do seu próprio insight analítico, já que ocorre um ataque ao vínculo capaz de integrar e transformar os elementos e conteúdos mentais díspares. Uma vez mais evocamos Bion, na medida em que ele nos sublinhou como o ataque ao vínculo tem repercussões sérias no processo de simbolização, uma vez que o símbolo é também ele um vínculo à realidade (ou seja, um vínculo entre os pensamentos e o que ocorre na realidade).

Por vezes, só após a ocorrência de uma descompensação inesperada é possível desvelarem-se com maior nitidez os fragmentos não nomeados e não representados que residem na parte psicótica da mente do paciente, até então "apartados" e inacessíveis do campo analítico.

Coloca-se incontornavelmente a questão sobre como a crise psicótica aguda, na perspetiva de De Masi (2006), parece emergir de núcleos delirantes infantis que permaneceram como que numa espécie de "beco", aguardando a possibilidade de se expressar.

Sendo, por vezes, difícil evitar-se o surgimento de um episódio psicótico no decurso de uma terapia, muitas vezes só conseguimos realmente compreender algum material clínico à luz desse evento disruptivo.

Com isto pretendemos sublinhar a ideia de que as ruturas, apesar de poderem acontecer de forma súbita e inesperada, têm usualmente uma longa história prévia escondida que necessita a dado momento de ser exteriorizada e vivida (para subsequentemente poder ser transformada e integrada).

Neste sentido, Sylvia Zwettler-Otte (2014) afirma o quanto as ruturas são frequentemente a face que apenas vemos à superfície quando não é possível continuar a negar que algo que foi desde sempre rejeitado finalmente emerge e irrompe de forma tantas vezes inesperada e desorganizadora.

Entendemos que o que ocorre não será da ordem de uma mera atualização, como se de uma recordação escondida se tratasse, mas antes a expressão da parte psicótica da realidade interna do paciente.

Filipe é um assistente social muito jovem, alto, entroncado, moreno, de expressão afetuosa e educada, mas simultaneamente algo tímido e contido. Fundamenta o seu pedido numa clara perceção das suas fortes dificuldades em manter uma relação amorosa estável e confiável, dando- 
-se conta de um padrão repetitivo tanto no estilo com que organiza a relação, como na escolha do tipo de namoradas que, invariavelmente, acabam por dececioná-lo e abandoná-lo.

Da sua história demarcam-se perdas múltiplas desde criança, como sejam uma depressão materna, (arrastada durante anos e associada a várias mortes num curto espaço de tempo) e a doença psiquiátrica do seu tio, com quem, após a morte prematura do pai, Filipe organizou uma relação paternal de grande proximidade e proteção. Quando este tio adoeceu a relação esboroou-se e deteriorou-se consideravelmente não mais voltando a ser reparada.

O processo analítico é vivido, durante o primeiro ano, de uma forma muito empenhada e investida, marcado por associações e fantasias particularmente ricas, associadas a sonhos abundantes e simbolicamente muito ricos. A transferência é ainda nesta fase muito idealizada, sublinhando-se simultaneamente a necessidade de manter uma certa distância defensiva em face dos núcleos mais destrutivos do self, os quais teme que possam ter um efeito devastador em si, mas também na analista.

Aproxima-se uma pausa prevista de uma semana no processo analítico, durante a qual viemos a saber mais tarde ter havido um reencontro sexual com uma ex-namorada, num contexto de noites mal dormidas, festas e consumos deálcool.

É neste quadro de separação da analista que ocorre uma descompensação grave com necessidade de internamento psiquiátrico (porém, de evolução rápida e favorável e com remissão total da sintomatologia).

Apesar da tensão crescente que estava a ser vivida pelo paciente, este episódio psicótico revelou-se francamente inesperado, já que irrompeu numa fase de pleno progresso analítico. Sentimos assim a necessidade de nos questionarmos sob diferentes formas: Teria sido possível, nas sessões anteriores a esta descompensação, prever ou intuir a ocorrência de uma rutura psíquica tão séria?

Revemos as sessões anteriores, com particular atenção para um sonho que Filipe havia trazido na última sessão antes da pausa: estava acom- panhado de um homem que subitamente cai ao seu lado e parece morrer fulminantemente. Desesperado, vendo uma enorme cavidade no corpo do sujeito faz manobras de ressuscitação. O homem começa a ganhar cor, a respirar e a voltar à vida. No entanto, sente-se muito aflito receando que ele tenha ficado com lesões cerebrais. É com pavor que percebe que a cara dele está desfigurada e cadavérica.

Filipe associa este homem ao seu pai, como se ainda não tivesse desistido de o ressuscitar (nas suas palavras). Pensamos também que por identificação e fidelidade a uma mãe que nunca organizou o "luto", com outra associação inconsciente possível ao seu tio/pai, igualmente perdido e ao qual permanecia internamente ligado. No excurso reflexivo associa depois, com algum sobressalto, este homem quase morto a ele mesmo, lutando para ser ressuscitado.

Ora, apesar de não termos deixado de trabalhar este material na sessão, ponderando o impacto desta sua parte moribunda e cadavérica que o arrasta para a morte da sua vida amorosa, interrogamo-nos à luz da disrupção psicótica se este sonho poderia representar também o confronto de Filipe com a parte psicótica da sua personalidade, que enfim reclamava uma expressão até então silenciada?

A cavidade que descobre no corpo do homem não poderá remeter para os seus núcleos traumáticos, não representados simbolicamente e inscritos numa espécie de registo de destrutividade omnipotente, que terão feito romper a capacidade integrativa do eu? Como se evocasse algo próximo de uma primeira vivência da angústia psicótica que surge no lugar do não representado, de algo que até então estava clivado, negado e projetado no tio (enquanto representante externo das suas partes loucas).

Um episódio como este é inegavelmente um evento de cariz traumático e desestruturante passível de imprimir marcas profundas no paciente, requerendo da dupla analítica um complexo trabalho de elaboração e de reconstrução. Também para o próprio analista, que sob uma situação de grande pressão se sente testado na sua capacidade de suportar e conter a explosão 
psicótica e de a pensar subsequentemente (pelo ataque imobilizante à sua função analítica).

Encontrando-se o ego do paciente afetado na sua capacidade de simbolização, igualmente assustado com a fragilidade da sua mente que acreditava ser inabalável (de certo modo reforçada pelo poder e idealização que Filipe atribuía ao processo analítico), sentimos que as tentativas de compreensão na pós-crise psicótica evocavam, por vezes, uma clara resistência no paciente, que evitava confrontar-se com o sucedido, tendendo a embotar ou dissociar a situação de crise, tentando continuar como se nada tivesse acontecido, ou permitindo apenas uma abordagem superficial ou intelectual do sucedido.

Franco De Masi (2006; 2015), a propósito destes momentos delicados, sublinha o risco destes episódios poderem organizar-se na dupla analítica como uma espécie de terceiro elemento inconveniente. Nesta linha, diz-nos o autor, que a resistência do paciente ao trabalho sobre a crise psicótica pode ser compreendida recorrendo à seguinte metáfora: tal como é difícil para um sobrevivente de uma catástrofe reviver o terror e a ausência de sentido na violência à qual foi sujeito, também para o paciente é muito difícil entrar de novo em contacto com a experiência disruptiva e o impacto catastrófico da parte louca da sua mente. Repensar a crise estimula a área da mente que criou o pensamento delirante, logo o medo subsequente de ser de novo invadido por ele.

Neste campo colocamos concomitantemente uma questão incontornável: e o que se passa com analista? Ou, em particular, com o risco da resistência do próprio analista em entrar em contacto com algo que pode, na sua fantasia, evocar o lugar onde se sente responsável pelo sucedido e, por isso, inseguro?

Estes aspetos poderão levar o analista a concentrar-se fundamentalmente na reparação dos danos de natureza narcísica do paciente, na necessidade de reassegurar a sua identidade e na procura da recuperação do seu funcionamento mental.

Não pondo em dúvida a importância desta componente na intervenção, sabemos, porém, como a subjetividade de cada terapeuta, nomea- damente em termos contratransferenciais, poderá facilitar, ou não, a via da elaboração profunda da rutura psicótica, fazendo notar, tal como diz Cassorla (1999; 2018), que essa elaboração tem lugar, antes de mais, na mente do analista.

Num campo analítico que pode ser ocupado por áreas não simbólicas, onde a capacidade de pensar do paciente, ou mesmo do par, estão enfraquecidas, cabe ao analista o esforço essencial de transformação dos elementos fragmentados e não simbolizados em elementos figuráveis e integráveis.

O paciente em rutura força-nos vividamente a sair da situação analítica e do pensamento analítico, uma vez que a violência e qualidade das suas identificações projetivas convidam à desorganização do pensamento.

Mas colocam também o analista perante si mesmo enquanto pessoa real, em face das suas próprias identificações de objeto e experiências arcaicas.

Se é verdade que o fenómeno transferencial é fator crucial do processo analítico, não é menos verdade que a resposta contratransferencial assume igual relevância, pelo que acreditar que o analista não responde e não se deixa afetar pelo vivido do paciente é evitar pensar nas questões de que depende o próprio processo psicanalítico. Steiner (2011) faz-nos notar como o analista, perante uma situação difícil de tolerar e integrar contratransferencialmente pode, por vezes, resvalar para o enactment em vez de compreender o papel que foi "convidado" a assumir.

Numa perspetiva intersubjetiva, recordamos também Winnicott (1949) quando nos diz que nada ocorre com um dos membros da dupla analítica que não seja capaz de influenciar o outro.

De facto, suportar a incerteza, a surpresa, o não saber ou compreender, o estranho, as dúvidas sobre o tempo e o tom da interpretação, a sua excessiva saturação ou eventual escassez, a dúvida sobre a capacidade de o paciente suportar a dor e a gestão dos silêncios são diversos aspetos que reenviam às dificuldades com que nos deparamos frequentemente. O manejo do setting externo nas circunstâncias impostas pela ocorrên- 
cia da rutura, como sejam a pausa por um tempo superior ao previsto, a retoma do processo a um ritmo diferente, neste caso mediado pelo impacto da medicação neuroléptica, a introdução de outros profissionais de saúde mental, nomeadamente do psiquiatra, e a necessidade do contato com os familiares são outros factores que interferem do campo analítico, mas que, sendo reais e inegáveis, não podem deixar de ser maneados pela psicanalista. E é neste contexto que se sublinha a necessidade premente de se manter viva a função analítica dentro da mente do analista.

Cremos que a dado momento é inevitável darmo-nos conta de como tudo isto nos permite relembrar as limitações e as fronteiras do método analítico. Não tanto no sentido negativo, mas antes como uma oportunidade preciosa de introjeção de algo especialmente importante: aquilo a que Roosevelt Cassorla (1999) designou objeto anti-omnipotência. $\mathrm{O}$ analista deve permitir-se perceber e tolerar as naturais limitações do seu método. Mas é também a consciência do analista de que, apesar das sérias dificuldades com que se debate o par analítico e das suas próprias limitações, poderá ainda assim proporcionar ao paciente a vivência de que não destruiu o analista, nem a análise. Isto remete-nos, com particular relevância, ao setting interno, ou mental. Se o externo pode ser alterado transitoriamente em função das circunstâncias especiais, o setting interno será, sem dúvida, o lugar onde o analista organiza uma película contentora suficientemente flexível para conter e transformar os diferentes fenómenos que ali ocorrem. Luz (2009), num interessantíssimo trabalho acerca de uma paciente particularmente difícil e desafiadora, sublinha, fundamentando-se em Bion e Winnicott, a especial necessidade do analista ser capaz de se transformar em algo que o paciente necessita que ele seja.

Deste modo, compreendemos que num contexto onde promovemos a ampliação do universo mental, não nos limitando de todo a desvelar algo que estava escondido ou "encurralado", trabalhamos no sentido de tornar possíveis as representações mentais de situações emocionais e subsequentemente rearticular significações de planos simbólicos distintos.

Com Filipe percebemos que, se antes ele parecia temer a ligação e a proximidade mais autênticas, tanto na relação com o outro, incluindo a analista, como na relação consigo mesmo (mobilizando um impressionante leque de defesas psíquicas contra esses contatos) essa dinâmica foi-se claramente atenuando e tornando-se menos árdua. Para tal, cremos ter sido fundamental o reconhecimento pelo paciente de que durante anos houve uma parte de si que se manteve clivada de uma outra parte sua francamente frágil e desnutrida. Este seu lado, não tendo sido assumido ou sentido, encontrava-se, pois, à míngua e inacessível à integração e elaboração, até pelo seu inegável caráter sabotador e mortífero.

Terminamos, enfim, com Bion (1962) e com a sua ideia de que um dos principais fins da análise é a de procurar que o paciente se veja a si mesmo, mais do que tentar mudá-lo. Ou como Ogden (2008) reafirma, mais do que ajudar o paciente a resolver os seus conflitos intrapsíquicos inconscientes, a nobre tarefa da psicanálise é a de ajudar o sujeito a desenvolver a sua própria capacidade para pensar e sentir as suas experiências emocionais.

\section{BIBLIOGRAFIA}

Bion, W. (1957), Differentiation of the psychotic from the non-psychotic personalities. International Journal of Psychoanalysis, 38: 266-275.

Bion, W. (1962). A theory of thinking. International Journal of Psychoanalysis, 43:306-310.

Bion, W. (1963;(1966)). Elementos de psicoanálisis. Buenos Aires: Paidós.

Cassorla, R. (1999). Psicanálise e surto psicótico: Considerações sobre aspectos técnicos. Comunicação apresentada no Congresso Brasileiro de Psicanálise, Rio de Janeiro.

Cassorla, R. (2018). In search of Symbolizations: the analyst task of dreaming, in: H. B. Levine, G. S. Reed, \& D. Scarfone (Eds.), Unrepresented States and the Construction of MeaningClinical and Theoretical Contributions (pp. 202 -219). London: Karnac. 
De Masi, F. (2006). Vulnerability to psychosis: A psychoanalytic study of the nature and therapy of the psychotic state. London: Karnac.

De Masi, F. (2015). Working with difficult patients - From neurosis to psychosis. London: Karnac.

Luz, A. B. (2009). Truth as a way of developing and preserving the space for thinking in the minds of the patient and the analyst. International Journal of Psychoanalysis, 90, 2: 291-310.

Ogden, T.H. (2008). Bion's four principles of mental functioning. Fort $\mathrm{Da}$, 14:11-35

Segal, H. (1957). Notes on symbol formation. In- ternational Journal of Psychoanalysis, 38: 391397.

Segal, H. (1978). On symbolism. International Journal of Psychoanalysis, 59:315-319.

Steiner, J. (2011). Seeing and being seen. Emerging from a Psychic Retreat. London: Routledge.

Winnicott, D. (1949). Hate in the countertransference. International Journal of Psychoanalysis, 30: 69-74.

Zwettler-Otte, S. (2014). A mosaic of ruptures. The EPF Bulletin, 68: 105.

\title{
Psychotic rupture and the analytical experience
}

\begin{abstract}
The author makes essential assumptions about the symbolization process and its failure to address how the unnamed and unrepresented elements that inhabit the psychotic part of the patient's mind maintain an area of the mind inaccessible to the analytic process, thus enhancing the outbreak of serious psychic rupture. Such ruptures are sometimes as surprising as they are unexpected and pose unavoidable difficulties in the experience and management of the analytical process. The importance of the analyst's internal setting is then underlined as a container film capable of transforming and integrating the different phenomena that occur in the analytic session.
\end{abstract}

Keywords

Psychotic rupture, Analytical experience, Failure in the symbolization

process 